\title{
As cartas na tragédia grega
}

\author{
FILOMENA YOSHIE HIRATA \\ Faculdade de Filosofia, Letras e Ciências Humanas \\ Universidade de São Paulo
}

\begin{abstract}
RESUMO: A revolução cultural provocada pela escrita não passou despercebida à cena trágica. Prova disso é a presença das cartas em algumas peças de Eurípides, dos últimos decênios do século V. Alguns exemplos são bastante curiosos, do ponto de vista da representação e da ação dramática. De repente a carta ocupa a cena e o público a vê, passando de mão em mão, entre as personagens do drama. Mas o mais notável é que ela exerce influência considerável no desenrolar da ação dramática. Pondo em relevo os empregos do termo déltos, este trabalho tem simplesmente o objetivo de examinar as cartas da tragédia e verificar o sentido delas no conflito trágico.
\end{abstract}

PALAVRAS-CHAVE: tragédia grega; déltos; tábua; carta; escrita; oralidade.

Déltos, em grego, corresponde a tabula no latim e a tábua em português: tabuinha ou tablete, quando se pensa no tamanho da peça de cerâmica encerada em que se escrevia, ou carta, uma tradução muitas vezes apropriada. As tragédias gregas trazem à cena algumas cartas: a de Fedra, no Hipólito, a de Ifigênia, em Ifigênia em Táurida, e a de Agamenão, em Ifigênia em Áulis. Todas são de Eurípides e certamente não por acaso, pois, atento ao que se passava ao redor e mais propenso a introduzir em seus dramas fatos de seu tempo, Eurípides talvez estivesse simplesmente trazendo à cena uma prática que se difundia e que ele provavelmente usava.

Como o título indica, não vou tratar de questões grandes e difíceis que tentam mostrar a influência da escrita na composição de um texto que será representado oralmente. Vários estudiosos já o fizeram com muita pertinência e arrojamento ${ }^{1}$. Meu objetivo é mais simples: apenas destacar os usos do substantivo déltos nas tragédias e tentar verificar-lhes o sentido.

Ainda que as cartas apareçam em cena apenas com Eurípides, penso ser importante anotar um curioso emprego de déltos no Prometeu Acorrentado, de Ésquilo ${ }^{2}$. Trata-se do segundo episódio, o momento em que Prometeu dialoga com Ió. Sim, numa peça que se passa entre deuses, ela é um dos visitantes, a única mortal, que chega ao lugar inóspito e distante, em que Prometeu está preso. Defrontam-se, de um lado, Ió, movimentando-se sem parar, o que faz parte de sua doença, e, de outro, Prometeu, imóvel, o que faz parte de seu castigo. Nesse momento ambos sofrem duramente nas mãos de Zeus. Diante da insistência de Ió, Prometeu decide predizer-lhe o futuro e então recomenda: 
A ti primeiro Ió direi a errância turbulenta, Escreve-a nas tábuas da memória do espírito (788-789)3.

A expressão é forte - escreve-a nas tábuas da memória do espírito (engráphou mnémosin déltois phrenôn) - e precisa ser, pois o que vem a seguir é uma previsão, que inclui a turbulenta errância (polýdonon plánen), ou seja, a mais longa viagem relatada numa tragédia, e Ió, em meio a acessos de loucura, deve ouvi-la e gravá-la na memória. Tudo diz respeito a ela: sua errância restante (loipèn plánen) e seu libertador (tòn lýsonta). O termo déltos, bem concreto e de uso recente, reforçado pelo verbo engráphou, no imperativo, aliase a outro mnémosin, da mesma família de mnemosýne, mais comum na tradição arcaica, deixando assim entrever esse momento de confronto entre oralidade e escrita ${ }^{4}$.

No entanto, o longo relato de Prometeu, essa espécie de curiosa divagação geográfica, que Ió deve reter, não acarreta nenhuma reviravolta no drama. Ió parte tão louca quanto quando entrou e, depois do que ouve, nenhuma esperança a mantém em suas longas viagens. O que Prometeu prevê, diz respeito a um futuro longínquo: um dia, no Egito, ela dará à luz Épafo e livrar-se-á de sua doença. Da mesma forma, num futuro longínquo, na última peça da trilogia, Prometeu será libertado e receberá sua função oficial e ritual.

Em As traquínias, de Sófocles, há referência a duas déltoi. A primeira déltos, uma espécie de carta-testamento, é deixada por Héracles a Dejanira, antes de partir (v. 47 e v. 157). A carta dá maus pressentimentos a Dejanira, pois nela Héracles previa a partilha de seu patrimônio entre ela e seus filhos; ele também falava de um fim, que podia ser o fim da vida ou dos trabalhos. E tinha fixado um prazo para a realização disso: quinze meses. Era, segundo ele, o que os deuses haviam estabelecido em relação ao fim dos trabalhos de Héracles.

Se, de um lado, uma espécie de carta-testamento, no início da peça, cria certa expectativa de morte face à longa ausência de Héracles, de outro, uma outra espécie de carta, uma inscrição gravada na memória, efetua a morte. E a tensão dramática, no tempo que separa as duas cartas, se faz sentir, porque a primeira preocupação com a morte é dissipada com a notícia de que Héracles está vivo. E tem mais: ele volta para casa, trazendo consigo uma bela e jovem concubina por quem destruíra a Ecália e com quem Dejanira haveria de conviver. Tomada pelo ciúme, por sentimentos confusos e obscuros, tão pertinentes aos domínios de Afrodite, Dejanira se recorda da déltos, mensagem, conselho que o centauro Nesso lhe dera ao morrer, atingido por flecha certeira de Héracles, quando tentava tocá-la com as mãos insolentes na travessia do Eveno:

Sofrendo nos flancos por uma flecha amarga,

o Centauro me fez recomendações, e eu não esqueci

nenhuma; mas guardei-as como uma inscrição

de uma tábua de bronze, que a água não apaga (680-683).

É mais um exemplo forte: inscrição gravada de uma tábua de bronze (khalkês déltou graphén), que alia à força da expressão a riqueza de sentido. Não existe concretamente uma tábua de bronze; portanto, esta é equivalente à tábua da memória do espírito de Prometeu. Mas, diferente do Prometeu, a inscrição tem consequiências no drama. Os conselhos do 
centauro, no momento da morte, são tão sedutores que se inscrevem, se fixam como uma inscrição, graphé, na memória de Dejanira:

Se o sangue coagulado da minha ferida recolheres com as mãos do lugar onde o sangue da hidra de Lerna tingiu a flecha de negro, ele será para ti um encantamento no coração de Héracles, a ponto de nunca mais amar nenhuma mulher que vir no lugar de ti (572-577).

Assim, Dejanira, no seu quarto, recinto de solidão, silêncio e intimidade, seduzida pelas palavras de Nesso, decide tornar para sempre seu o amor de Héracles. Na seqüência, serve-se da poção mágica, untando uma túnica e enviando-a a Héracles, para que ele a vestisse no momento da realização das oferendas a Zeus, no cabo Ceneu, na Eubéia. Servindo-se da poção mágica, ela materializa o que está inscrito na tábua de bronze num veneno poderoso, capaz de ultrapassar os limites da casa e levar a desgraça a longas distâncias. Héracles morre devorado pela túnica que se ajusta a seu corpo, atingido por um conselho enganoso e ambíguo, vindo de um morto, submisso ao poder de Cípris.

Nas tragédias de Eurípides, a déltos não é apenas mencionada, uma referência, mas aparece em cena, faz parte da representação teatral, é manipulada pelas personagens e é visível ao espectador. Acho que podemos começar pela carta de Fedra, que aparece no Hipólito, por causa da associação quase imediata que fazemos entre Fedra e Dejanira, uma vez que ambas agem sob o poder de Afrodite. Apaixonada pelo enteado Hipólito até os limites da loucura e rejeitada por ele a altos brados, quando o amor lhe é revelado pela ama, Fedra se suicida, mas não sem antes escrever uma carta ao marido, resguardando a honra. Sua última intenção é revelada ao público antes de deixar a cena:

$$
\begin{aligned}
& \text {...por amargo amor serei derrotada, } \\
& \text { mas um mal para um outro serei, morta, } \\
& \text { para que aprenda a não ser orgulhoso } \\
& \text { diante de meus males (727-730). }
\end{aligned}
$$

O que ela diz pode parecer um pouco espantoso a princípio, mas sua ação na sequiência é implacável: o suicídio. Teseu, em meio a terrível sofrimento, olha a mulher morta e descobre a carta que lhe pende da mão. A cena é lentamente preparada. Do grito da serva, anunciando a morte de Fedra, até a descoberta da carta, são oitenta versos de lamentações, como se Eurípides acreditasse no trunfo que tinha nas mãos, ou seja, numa grande cena de impacto, jogando o destino do drama numa carta. Ele a lê e diz:

Grita, a carta grita horrores! Aonde fugir do peso dos males? Pois eu me vou aniquilado. Tal, tal é o canto que vi falar nessa escrita, infeliz (877-880). 
Em grego, boãi, boãi déltos álasta. A frase é simples e forte. A carta grita coisas horríveis, isto é, álasta, como o alástor, que traz golpes horríveis, cruéis ${ }^{5}$. Impossível deixar de reter a personificação. A carta grita; ela é a pessoa que escreve ${ }^{6}$. É como se Fedra estivesse ali falando. E da mesma forma, nos versos seguintes, a linguagem enfática persiste: o que está escrito (en graphaîs) chega ao leitor como um canto que fala (mélos phthengómenon). Contudo, nós desconhecemos o que Fedra realmente escreveu. Sabemos o que Teseu nos transmite:

Hipólito ousou tocar em meu leito por violência, desonrando o olhar solene de Zeus (886-887).

Teseu, persuadido pela mensagem, sem titubear, pragueja contra o filho, rogando-lhe as maldições de Poseidon, privilégio seu, que condenam Hipólito irremediavelmente à morte. Nesse momento de desespero e cegueira, todos tentam chamá-lo à razão, o coro e o próprio Hipólito, que entra em cena ao ouvir os gritos do pai. Contudo fica estupefato, ao ver morta Fedra, e, mais ainda, ao ver-se acusado como responsável pela morte. Tem condições de defender-se, mas seus argumentos mal chegam aos ouvidos do pai irado. Conseqüentemente, a carta cheia de mentiras, de uma morta, realiza um feito devastador, pois é muito mais convincente do que as palavras ditas por Hipólito que, inocente, grita por sua inocência. Como escreve Charles Segal (1982, p. 149), "a clivagem entre discurso escrito e falado, locutor visível e invisível, corresponde a uma clivagem entre verdade e mentira (cf. apate, v. 931), na qual Hipólito é tragicamente pego: a tabuinha falante prova que o inocente é culpado e inocenta a culpada”.

De Eurípides também nos chegaram as cartas de Agamenão, na Ifigênia em Áulis. No prólogo, por meio de um diálogo entre o rei Agamenão e um velho escravo, ficamos sabendo que já é noite avançada e todos dormem, que tudo está tranqüilo em Áulis, apenas Agamenão não está tranquiilo. A tormenta que o devasta e lhe tira o sono, vem na forma de uma hesitação, de uma dúvida cruel, que se resolveria na redução de uma alternativa. Quem observa o que se passa no interior da tenda e relata esse momento difícil do rei, é o velho escravo:

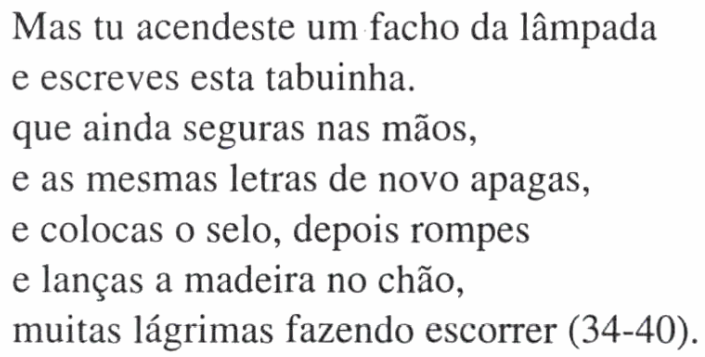

De fato Agamenão encontra-se numa situação aporética. De um lado, a armada grega, reunida em Áulis, está pronta para partir, mas não há ventos; de outro, o adivinho Calcas revela que Ifigênia deveria ser imolada à deusa Ártemis, para que a travessia se fizesse e os frígios fossem vencidos. Agamenão opõe-se ao sacrifício da filha e propõe a dispersão da armada, mas cedendo aos apelos insistentes do irmão Menelau, acaba fazendo algo terrível. 
Nas dobras de uma carta (en déltou ptykhaîs), pede a Clitemnestra que envie a filha Ifigênia ao acampamento, sob pretexto de um excelente casamento, mas mentiroso, com Aquiles. Desse plano, além dos irmãos, apenas Ulisses e Calcas têm conhecimento. Essa primeira carta já fora enviada, antes que a peça começasse. Mas agora, arrependido da decisão anterior, quer impedir a vinda da filha; por isso escreve uma outra carta e pede ao velho escravo que a leve, às pressas e às escondidas, a Clitemnestra em Argos. Antes, porém, diz o conteúdo da carta ao velho, para que as palavras dele se harmonizassem com as da carta:

Envio-te, depois da carta precedente,

filha de Leda, esta para pedir

que não mandes tua filha

para a asa sinuosa da Eubéia

a Áulis sem ondas.

Em outro tempo

festejaremos o casamento da filha (115-121).

O objetivo da carta é impedir que Ifigênia venha a Áulis e seja sacrificada pelo pai em nome da armada grega. A hesitação do rei entre os valores do ô̂kos e os da pólis, como dois pratos de uma balança, nesse instante tende para os do ôk kos. A carta tenta impedir a dissolução da família. Mas o velho escravo é impedido de partir por Menelau; conseqüentemente a carta é interceptada e o conteúdo dela revelado. Na sequiência, Ifigênia chega e é sacrificada a Ártemis. Durante anos, a morte de Ifigênia alimentará o rancor de Clitemnestra e será a base da discórdia familiar. A carta, nesta tragédia, se apresenta como um instrumento de comunicação frágil. Devidamente lacrada, ela é confiada a um escravo velho e amigo, para que sua entrega seja garantida. Mas ela não dispensa o conhecimento do conteúdo. Mesmo assegurando essas condições, a mensagem de Agamenão não chega ao destinatário, porque as cartas ainda podem ser interceptadas ou perder-se pelos caminhos.

Na Ifigênia em Táurida, a carta é o instrumento fundamental, que provoca a inversão do desconhecido para o conhecido, isto é, o reconhecimento dos irmãos Orestes e Ifigênia, diante do amigo Pílades. A cena é longa e percebe-se que foi trabalhada com esmero por Eurípides. Mereceu de Aristóteles quatro citações na Poética e foi considerada a mais bela cena de reconhecimento, ao lado do de Édipo $\operatorname{Rei}^{7}$.

Nessa aventura euripidiana, Ifigênia, como ela própria relata no prólogo, não morre no sacrifício em Áulis ${ }^{8}$, mas é substituída por um cervo e levada a Táurida por Ártemis, onde cumpre a função de sacerdotisa dessa deusa, sacrificando todos os estrangeiros que chegam à região. E lá chega Orestes, acompanhado do amigo Pílades, em busca da estátua de Ártemis, cumprindo ainda essa exigência por causa da perseguição das Erínias.

Estamos, então, no segundo episódio, quando, pela primeira vez na tragédia, Ifigênia se defronta com Orestes e Pílades, feitos prisioneiros. Ifigênia não consegue disfarçar certa perturbação por estar diante de gregos, ainda que premida pela necessidade de ter de sacrificálos. O fato de serem gregos desperta estranha emoção, acalentada por confuso sonho da véspera, e aguça sua curiosidade, tanto que suas perguntas não passam despercebidas aos dois, porque mostram certo conhecimento e interesse por Argos. Mas toda indagação é bem contornada pelo poeta, a ponto de não pôr em risco o suspense da cena de reconhecimento. 
Por meio de algumas perguntas, Ifigênia vai rememorando seu passado perdido no tempo; de fato, é como se estivesse morta. Fica sabendo que Tróia caiu, que Helena retornou a Esparta com Menelau, que Calcas morreu, que Ulisses ainda não retornou a casa, e que Aquiles morreu. Esse primeiro lote de perguntas diz respeito à guerra. Depois as perguntas tornam-se mais familiares. Fica sabendo então que Agamenão morreu pela mão da mulher e esta, por sua vez, pela mão do filho. O filho vive vagando e Electra vive. Antes, porém, de encerrar esta sua dura reconstituição pela memória de sua família destruída, Ifigênia quer saber o que se diz dela. Que lógos existe sobre a filha sacrificada? Orestes responde que nenhum, apenas que ela não vê mais a luz. Considerada morta por todos, Ifigênia resolve viver, mostrar que a morta está viva, mas para tanto precisa agir. Pergunta, então, a Orestes se levaria uma carta a parentes seus em Argos, caso ela o deixasse livre? Orestes responde que é Pílades quem deve viver e levar a carta. Ele fica para morrer. Ifigênia concorda, elogiando a nobreza de caráter de Orestes, e sai para buscar a carta. Depois volta com ela nas mãos:

Aqui estão as múltiplas dobras da carta, estrangeiros (727).

A carta entra em cena e todos podem vê-la. Trata-se de uma mensagem longa, pois a déltos tem múltiplas dobras (Déltou haíde polýthyroi diaptykhaí), como Ifigênia anuncia. Depois a preocupação gira em torno da segurança da carta, para que ela chegue a seu destino. Ifigênia precisa de garantias de que Pílades realmente entregará a carta. E ele só vê um risco: que a carta se perca num naufrágio. Ifigênia decide, então, aumentar as possibilidades de comunicação, dizendo o conteúdo da carta:

Anuncia a Orestes, filho de Agamenão, isto:

eis o que aquela que foi sacrificada em Áulis,

Ifigênia, que está viva, mas aos daí está morta, escreve: (769-71)

conduze-me para Argos, ó irmão, desta terra bárbara,

antes que morra, e livra-me dos sacrifícios da deusa,

nos quais presido com honra a morte de estrangeiros (774-6).

Ou serei maldição para tua casa, Orestes (778-9).

Dize que a deusa Ártemis me salvou, trocando-me por um cervo, que meu pai sacrificou, pensando que me traspassava com a lança aguda, e trouxe-me a esta terra (783-6).

E finaliza:

Eis a mensagem, o que está escrito nas tabuinhas (786-7).

É impossível dizer que Orestes e Pílades conseguiam ouvir a leitura da mensagem (epistolai ), das coisas escritas (tà engegramména) na carta (en déltoisin) sem interrupção. 
Estavam atônitos e incrédulos. Ao final, Pílades entrega a carta a Orestes, cumprindo a tarefa facilmente, para espanto de Ifigênia. E Orestes, que mal consegue se conter diante do inesperado, pegando a carta, diz que prefere gozar de um prazer mais real do que abrir a carta, que é abraçar a irmã. Mas é justamente a irmã, que para todos estava morta, que quer provas de que o homem, que está na sua frente, é Orestes. E enquanto ele fornece essas provas, Eurípides prolonga e aprimora os efeitos dramáticos desse recurso técnico, digamos assim, que é a anagnórisis, acreditando que ele pode sustentar o interesse de boa parte da peça. E não errou, se pensarmos na importância que Aristóteles atribui a ele na Poética ${ }^{9}$.

A carta é, enfim, a peça fundamental para o reconhecimento dos dois irmãos. É importante dramaticamente. Mas enquanto instrumento de comunicação, é frágil, tem pouca credibilidade. Primeiro, desconfia-se de que ela chegue: o portador (no caso, Pílades) deve jurar pela própria vida que entregará a carta; segundo, cartas se extraviam: (num naufrágio, por exemplo) é mais seguro que o portador saiba o conteúdo delas.

\section{Notas}

1 - Cf. Segal, 1982 e Havelock, 1994.

2 - Não pretendo entrar aqui na discussão sobre a autoria dessa peça.

3 - O texto grego citado neste trabalho é o da Collection Guillaume Budé e as traduções são minhas.

4 - Em relação ao emprego de déltos com phrén, aparece no v. 275 do canto coral de As Eumênidas, a expressão deltográphoi....phrení, referindo-se a "Hades que observa tudo" e retém no espírito como numa tábua escrita.

5 - Barret não aceita a aproximação entre álasta e lanthánomai, o que permitiria a tradução de álasta por coisas inesquecíveis. Cf. Euripides, 1964, p. 332.

6 - Cf. Segal, 1982, p. 148.

7 - Cf. Aristóteles, Poética, 1452b5, 1454b30-5, 1455b2-11, 1455a 18-21.

8 - Eurípides manterá essa versão na Ifigênia em Áulis que é posterior.

9 - Aristóteles, Poética, capítulos 10, 11, 16.

\section{Referências bibliográficas}

\section{Textos:}

ARISTOTLE. Poetics. Introduction, commentary and appendixes by D. W. Lucas. Oxford: The Clarendon Press, 1972.

ESCHYLE. Les suppliantes, Les Perses, Les sept contre Thèbes, Prométhée enchainé. Texte établi et traduit par Paul Mazon. Paris: Société d’ Edition “Les Belles Lettres", 1969, tome I.

EURIPIDE. Hippolyte, Andromaque, Hécube. Texte établi et traduit par Louis Méridier. Paris: Société d'Edition "Les Belles Lettres", 1960, tome II.

Les troyennes, Iphigénie en Tauride,Électre. Texte établi et traduit par Léon Parmentier. Paris: Société d'Edition “Les Belles Lettres”, 1968, tome IV. 
Iphigénie à Aulis. Texte établi et traduit par François Jouan, Paris: Société d'Edition

"Les Belles Lettres", 1983, tome VII-1.

EURIPIDIS. Hippolytos. Edited with introduction and commentary by W. S. Barrett. Oxford:

Clarendon Press, 1964.

SOPHOCLE. Les Trachiniennes, Antigone. Texte établi par Alphonse Dain et traduit par

Paul Mazon. Paris: Société d' Edition “Les Belles Lettres”, 1955, tome I.

The plays of Sophocles, the Trachiniae, by J. C. Kamerbeek. Leiden: E. J. Brill, 1970.

\section{Obras gerais:}

BENEDETTO, V. \& MEDDA, E. La tragedia sulla scena. Torino: Einaudi, 1997.

DUNN, F. M. Tragedy's End. Oxford: Oxford University Press, 1996.

HAVELOCK, Eric. A revolução da escrita na Grécia. São Paulo: Ed. UNESP/ Paz e Terra, 1994.

MOLINARI, C. (Org.). Il teatro greco nell' età di Pericle. Bologna: Il Mulino, 1994.

SEGAL, C. P. "Tragédie, oralité, écriture”. In: Poétique, 50, Paris, Seuil, 1982, p.131-154. . "Verità, tragedia e scrittura". In: MOLINARI, Cesare (Org.). Il teatro greco nell'età di Pericle. Bologna: Il Mulino, 1994.

HIRATA, Filomena Yoshie. Les lettres dans la tragédie grecque. Classica, São Paulo, 13/ 14. p. $315-322,2000 / 2001$.

RÉSUMÉ: La révolution culturelle provoquée par l' écriture n'a pas échappé à la scène tragique. La présence des lettres dans quelques pièces d'Euripide des dernières décennies du $V^{e}$ siècle le prouve. Ce sont des exemples assez curieux du point de vue de la mise-en-scène et de l'action dramatique. La lettre apparaît soudain en scène et le publique la voit passant de main en main entre les personnages. Mais le plus remarquable c'est qu'elle exerce une influence considérable dans le développement de l'action dramatique. Relevant les emplois du mot déltos, ce travail envisage tout simplement d'examiner les lettres de la tragédie et de vérifier leur sens dans le conflit tragique.

MOTS-CLÉS: tragédie grecque; déltos; lettre; tablette; écriture; oralité. 